\title{
Age dependency of safety and outcome of endovascular therapy for acute stroke
}

\author{
Rudolf Luedi · Kety Hsieh • Agnieszka Slezak • Marwan El-Koussy • \\ Urs Fischer • Mirjam R. Heldner · Julia Meisterernst • Marie-Luise Mono • \\ Christoph Zubler · Pasquale Mordasini - Christoph Ozdoba - Heinrich P. Mattle • \\ Gerhard Schroth · Jan Gralla $\cdot$ Marcel Arnold $\cdot$ Simon Jung
}

Received: 5 March 2014/Revised: 1 June 2014/Accepted: 4 June 2014/Published online: 11 June 2014

(c) Springer-Verlag Berlin Heidelberg 2014

\begin{abstract}
Elderly patients generally experience less favorable outcomes and higher mortality after acute stroke than younger patients. The aim of this study was to analyze the influence of age on outcome and safety after endovascular therapy in a large cohort of patients aged between 20 and 90 years. We prospectively acquired data of 1,000 stroke patients treated with endovascular therapy at a single center. Logistic regression analysis was performed to determine predictors of outcome and linear regression analysis to evaluate the association of age and outcome after 3 months. Younger age was an independent predictor of favorable outcome (OR $0.954, p<0.001$ ) and survival (OR 0.947, $p<0.001$ ) in multivariate regression analysis. There was a linear relationship between age and outcome. Ever increase in 26 years of age was associated with an increase in the modified Rankin Scale of 1 point $(p<0.001)$. However, increasing age was not a risk factor for symptomatic $(p=0.086)$ or asymptomatic $(p=0.674)$ intracerebral hemorrhage and did not influence recanalization success $(p=0.674)$. Advancing age was associated
\end{abstract}

R. Luedi, K. Hsieh, M. Arnold and S. Jung have contributed equally to this work.

R. Luedi · A. Slezak · U. Fischer · M. R. Heldner ·

J. Meisterernst · M.-L. Mono - C. Zubler · P. Mordasini .

H. P. Mattle $(\varangle) \cdot$ M. Arnold · S. Jung

Department of Neurology, Inselspital, University Hospital Bern and University of Bern, Freiburgstrasse 10, 3010 Bern,

Switzerland

e-mail: heinrich.mattle@insel.ch

K. Hsieh · A. Slezak · M. El-Koussy · C. Ozdoba ·

G. Schroth $\cdot$ J. Gralla $\cdot$ S. Jung

Department of Diagnostic and Interventional Neuroradiology, Inselspital, University Hospital Bern and University of Bern,

Bern, Switzerland with a decline of favorable outcomes and survival after endovascular therapy. This decline was linear from age 20 to 90 years, but was not related to lower recanalization rates or higher bleeding risk in the elderly. The efficacy of endovascular stroke therapy seems to be preserved also in the elderly and other factors than efficacy of endovascular therapy such as decreased plasticity are likely to explain the worse outcome with advancing age.

Keywords Intra-arterial thrombolysis · Endovascular therapy $\cdot$ Outcome $\cdot$ Age

\section{Introduction}

Outcome after stroke is known to be less favorable in elderly patients and mortality is increased compared to younger ones [1-3]. Intravenous thrombolysis (IVT) improves outcome and can be performed safely both in younger and elderly patients but outcome in the elderly is still less favorable than in younger patients [4-13].

Endovascular treatment trials such as and IMS 1, IMS 2, and SYNTHESIS excluded patients older than 80 years [14-16]. Only PROACT II, IMS 3 and MR Rescue included patients up to 85 years [17-19]. In a previous analysis, we found similar rates of recanalization and symptomatic intracerebral hemorrhages (ICH) after endovascular treatment in our patients older than 80 years compared to our younger patients but outcomes were generally less favorable and survival decreased [20]. These results concur with the results of other studies on endovascular-treated patients [21-24].

Almost all studies that addressed the outcome of elderly people after acute stroke dichotomized patients according to patients' age with a cutoff of 80 years. This categorical 
handling of age leads to the impression that 80 years is a critical age, after which outcome becomes worse. However, age seems to be an independent predictor of outcome also in patients younger than 80 years [25].

The aim of this study was to analyze the influence of age on outcome and safety after endovascular therapy for acute stroke is in a large cohort of patients aged between 20 and 90 years.

\section{Patients and methods}

Patients

From May 1992 to June 2012, we treated 1,000 patients aged between 20 and 90 years with endovascular therapy. Some aspects of these patients have been reported previously [20, 26, 27].

A neurologist examined all patients immediately after admission to the emergency room and the neurologic deficit was scored using the National Institutes of Health Stroke Scale (NIHSS). Demographic and clinical data were recorded [age, gender, time of symptom onset, coronary artery disease, atrial fibrillation, hypertension, diabetes, current smoking, hypercholesterolemia according to history or current lipid values, history of transient ischemic attack (TIA) or ischemic stroke]. Afterwards, patients underwent computed tomography (CT) or magnetic resonance imaging (MRI). Endovascular therapy was performed with the consent of the patient or his family immediately after CT or MRI if: (1) diagnosis of ischemic stroke was established; (2) baseline NIHSS score was $\geq 4$ points or isolated aphasia or hemianopia was present; (3) hemorrhage on cranial CT or MRI was excluded; (4) vessel occlusion correlated with the neurological deficit; and (5) no individual clinical or premorbid conditions or laboratory findings advised against thrombolysis. Digital subtraction angiography (DSA) was performed via a transfemoral approach using a biplane, high-resolution angiography system (1992-2006: CAS 2006, Toshiba, since 2007: Axiom Artis Zee, Siemens, Erlangen, Germany). In general, four vessel cerebral angiography was performed. Collaterals were classified as previously reported [25]. The interventional neuroradiologists decided jointly with the neurologist on the use of urokinase, mechanical intervention [mainly aspiration and stent retriever since 2009; Penumbra and Merci devices have rarely been used $(n<10)$ and fragmentation of the thrombus was avoided whenever possible] or both as recanalization techniques. At the end of the intervention, recanalization was classified according to thrombolysis in myocardial infarction (TIMI) grades.

A CT or MRI scan was obtained 24-72 h after treatment or in any case of clinical deterioration. Symptomatic (sICH) and asymptomatic intracranial bleedings $(\mathrm{aICH})$ were graded according to the PROACT II Study [28]. Clinical outcome was assessed 3 months after the stroke using the modified Rankin Scale (mRS).

The study was performed according to the ethical guidelines of the Canton of Bern and with corresponding permission.

\section{Statistical analysis}

Statistical analysis was performed using SPSS 21 (SPSS Inc., Chicago, IL, USA). Categorical variables were

Table 1 Baseline characteristics and outcome of 1,000 patients after endovascular treatment

\begin{tabular}{|c|c|c|c|c|c|c|c|}
\hline & 20-29 years & 30-39 years & $40-49$ years & $50-59$ years & $60-69$ years & 70-79 years & 80-89 years \\
\hline$n$ & 17 & 28 & 99 & 171 & 259 & 298 & 128 \\
\hline Female sex & 9/17 (52.9) & $17 / 28(60.7)$ & $51 / 99(51.5)$ & $\begin{array}{r}52 / 171 \\
(30.4)\end{array}$ & $\begin{array}{c}100 / 259 \\
(38.6)\end{array}$ & $\begin{array}{c}141 / 298 \\
(47.3)\end{array}$ & $\begin{array}{r}77 / 128 \\
(60.2)\end{array}$ \\
\hline NIHSS, median (range) & $13(5-31)$ & $15(0-36)$ & $16(3-36)$ & $15(2-36)$ & $15(0-36)$ & $15(2-36)$ & $17(2-36)$ \\
\hline $\begin{array}{l}\text { Time to recanalization }(\mathrm{min}) \text {, median } \\
\text { (range) }\end{array}$ & $\begin{array}{l}240 \\
\quad(135-472)\end{array}$ & $\begin{array}{l}292 \\
\quad(15-971)\end{array}$ & $\begin{array}{l}270 \\
\quad(80-705)\end{array}$ & $\begin{array}{l}255 \\
(45-943)\end{array}$ & $\begin{array}{l}271 \\
\quad(18-1,210)\end{array}$ & $\begin{array}{l}269 \\
\quad(16-1,472)\end{array}$ & $\begin{array}{l}260 \\
\quad(77-1,440)\end{array}$ \\
\hline TIMI 2-3 recanalization & $13 / 16(81.3)$ & $22 / 28(78.6)$ & $76 / 99(76.8)$ & $\begin{array}{r}126 / 170 \\
(74.1)\end{array}$ & $\begin{array}{c}193 / 256 \\
(75.4)\end{array}$ & $\begin{array}{c}210 / 296 \\
(70.9)\end{array}$ & $\begin{array}{r}93 / 126 \\
(73.8)\end{array}$ \\
\hline Symptomatic ICH & 0 & 0 & 3/99 (3) & $9 / 171(5.3)$ & $16 / 258(6.2)$ & $24 / 297(8.1)$ & $9 / 126(7.1)$ \\
\hline Asymptomatic ICH & 2/17 (11.8) & $1 / 28(3.6)$ & 13/99 (13.1) & 34/17 (19.9) & $\begin{array}{r}44 / 258 \\
(17.1)\end{array}$ & $\begin{array}{r}59 / 296 \\
(19.9)\end{array}$ & $\begin{array}{r}21 / 126 \\
(16.7)\end{array}$ \\
\hline mRS 0-2 & $11 / 17(64.7)$ & $17 / 28(60.7)$ & $57 / 99(57.6)$ & $\begin{array}{r}92 / 169 \\
(54.4)\end{array}$ & $\begin{array}{c}120 / 258 \\
(46.5)\end{array}$ & $\begin{array}{c}114 / 296 \\
(38.5)\end{array}$ & $\begin{array}{r}26 / 128 \\
(20.3)\end{array}$ \\
\hline Survival & 17/17 (100) & $26 / 28(92.9)$ & $87 / 99$ (87.9) & $\begin{array}{r}144 / 169 \\
(85.1)\end{array}$ & $\begin{array}{c}197 / 258 \\
(76.4)\end{array}$ & $\begin{array}{c}214 / 296 \\
(72.3)\end{array}$ & $\begin{array}{r}77 / 128 \\
(60.2)\end{array}$ \\
\hline
\end{tabular}

$N(\%)$ if not indicated otherwise 
Table 2 Distribution of location of vessel occlusion, (\%)

\begin{tabular}{|c|c|c|c|c|c|c|c|}
\hline & 20-29 years & 30-39 years & $40-49$ years & $50-59$ years & $60-69$ years & 70-79 years & $80-89$ years \\
\hline ICA & 23.5 & 17.9 & 34.3 & 25.1 & 30.1 & 20.1 & 20.3 \\
\hline $\mathrm{MCA}$ & 58.8 & 57.1 & 43.4 & 58.5 & 53.7 & 63.8 & 67.2 \\
\hline BA & 17.6 & 21.4 & 20.2 & 14 & 12.8 & 14.1 & 12.5 \\
\hline $\mathrm{ACA}$ & 0 & 0 & 1 & 0.6 & 1.9 & 0 & 0 \\
\hline PCA & 0 & 3.6 & 1 & 1.8 & 1.5 & 2 & 0 \\
\hline
\end{tabular}

compared with $\chi^{2}$ and Fisher's exact test as appropriate and continuous variables with Mann-Whitney test. Outcome was dichotomized into favorable (mRS 0-2) and poor clinical outcome (mRS 3-6) and recanalization as seen on DSA into good (TIMI grades 2-3) and poor recanalization (TIMI grades 0-1). Forward stepwise logistic regression including all variables with $p<0.2$ in univariate analysis (age, gender, time to thrombolysis, NIHSS score on admission, atrial fibrillation, vessel dissection, diabetes, hypertension, hypercholesterolemia, coronary artery disease, previous stroke or TIA, smoking, family history of stroke, occlusion type, degree of collaterals, recanalization after IAT, dose of urokinase) was used to determine the predictors of clinical outcome, survival, recanalization and bleeding complications. A $p$ value $<0.05$ was considered significant. Linear regression analysis was used to analyze the relation between age and $\mathrm{mRS}$.

\section{Results}

Baseline characteristics and outcome of the 1,000 study patients are given in Tables 1 and 2 .
Fig. 1 Percentage of favorable outcome (mRS 0-2) and survival after 3 months for each life decade of 1,000 patients after endovascular treatment

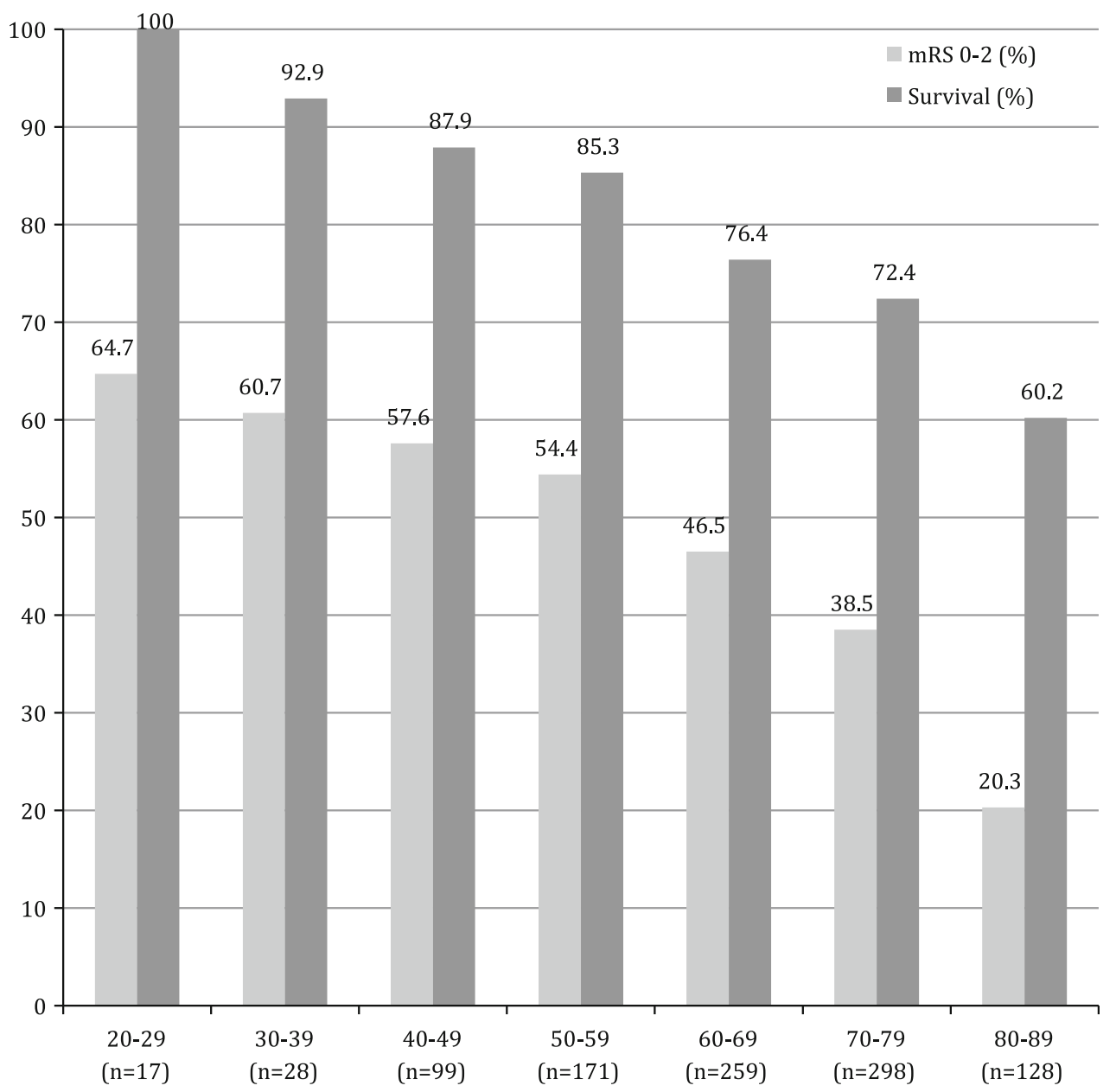


Fig. 2 a Mean modified Rankin Scale after 3 months for each life decade. b Distribution of modified Rankin Scale after 3 months for each life decade
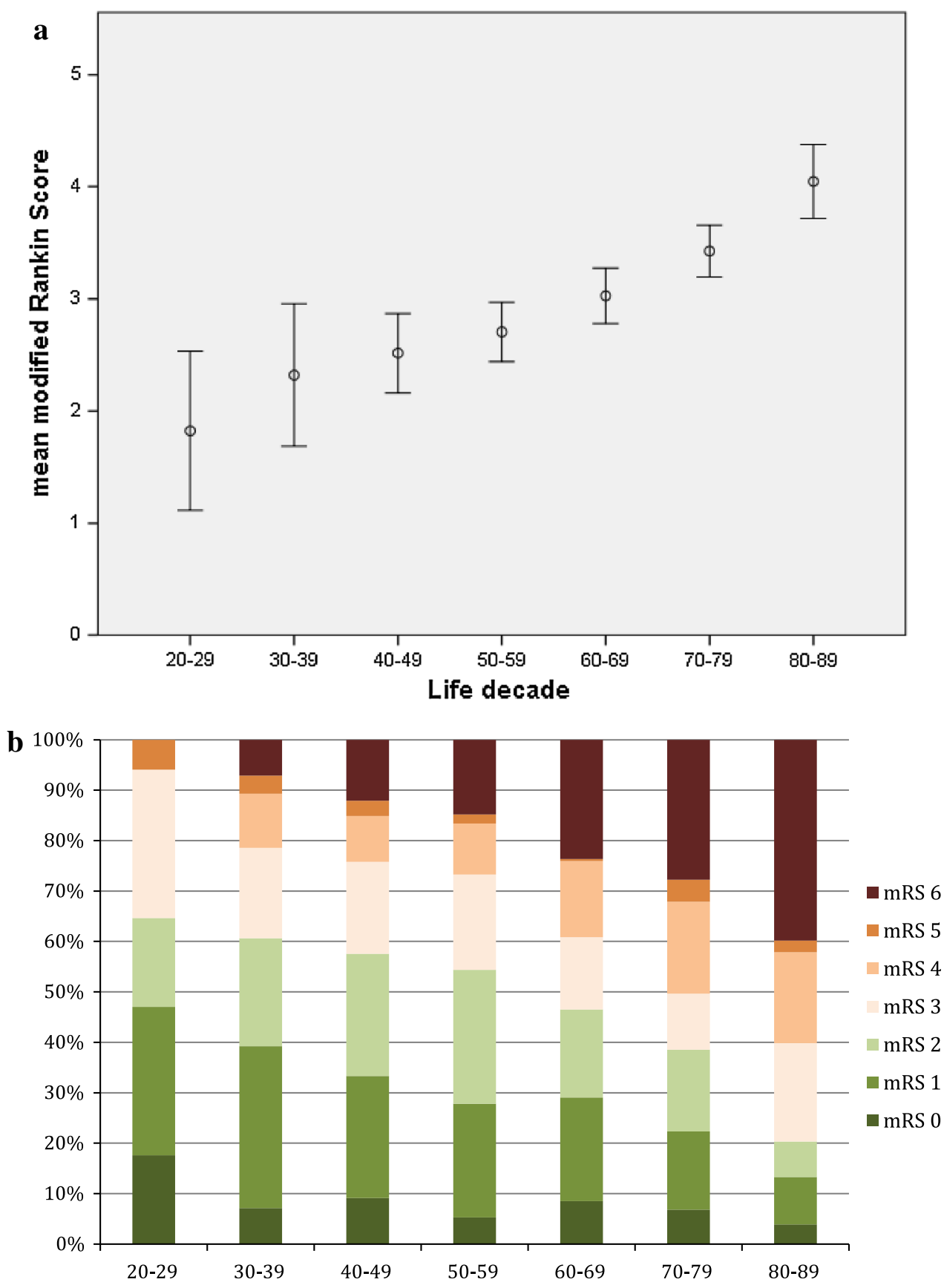

Advancing age was an independent predictor of unfavorable outcome in multivariable regression analysis $(p<0.001$, OR 0.954 ; other factors: NIHSS $p<0.001$, OR 0.870; recanalization $p<0.001$, OR 3.716; diabetes mellitus $p<0.001$, OR 0.383; hypercholesterolemia $p=0.007$, OR 1.586; collaterals $p=0.003$, OR 1.438; time to treatment $p=0.016$, OR 0.998 ; location of vessel occlusion $p<0.001$ ). Advancing age was also an independent predictor of mortality $(p<0.001$, OR 0.947 ; other factors: NIHSS $p<0.001$, OR 0.928 ; recanalization $p=0.001$, OR 1.906 ; diabetes mellitus $p=0.014$, OR
0.568 ; hypercholesterolemia $p=0.039$, OR 1.462 ; collaterals $p<0.001$, OR 1.878; location of vessel occlusion $p<0.001)$. There was a linear relationship between age and outcome. When outcome was assessed with the modified Rankin Scale the score increased by one point per 26 years age increase $(p<0.001)$ (Figs. 1,2$)$.

In multivariable regression analysis age did not predict symptomatic ICH (predicting factor: collaterals $p<0.001$, OR 0.432 ; age $p=0.086$ ) or asymptomatic ICH (predicting factors: atrial fibrillation $p=0.001$, OR 1.856; baseline NIHSS $p=0.010$, OR 1.036; age $p=0.674$ ). For 
TIMI 2-3 recanalization, we found the location of vessel occlusion $(p=0.010)$ and the quality of collaterals ( $p=0.026$, OR 1.276) as independent predictors, but not age $(p=0.674)$.

\section{Discussion}

The chances for favorable outcome after acute stroke and endovascular stroke therapy decline continuously with advancing age from 20 to 90 years in a linear manner. This is the main finding of our study. The mean modified Rankin Score 3 months after the stroke increases by 1 point every 26 years of age increase; however, this age-related decline of favorable outcome is not related to lower recanalization rates or higher bleeding risk in the elderly.

Since stroke incidence is increasing with advancing age and since life expectancy is growing in many societies, the treatment of elderly stroke patients is becoming a major issue in health care. There is growing evidence that IVT can be performed safely and effectively in elderly stroke patients, though the large intravenous and endovascular therapy trials included only patients up to 80 or 85 years old (NINDS; ECASS, PROACT, IMS 1+2) [4-13]. Nevertheless, outcome in the older stroke patients seems to be less favorable than in the younger.

In a previous study we showed that endovascular therapy in 43 patients aged older than 80 years was as safe as in 576 younger patients but clinical outcome was worse [20]. These results concur with other endovascular therapy studies that found worse outcome but not an increased risk for ICH in patients older than 80 years [21-24].

All endovascular treatment trials and most trials on IVT analyzed the influence of age in acute stroke therapy by dichotomizing patients with a cutoff value of 80 years. This categorical handling of age leads to the false impression that 80 years is a critical age, after which outcome becomes worse.

As expected, age was an independent predictor of outcome and survival in the present analysis of 1,000 stroke patients who received endovascular treatment. Moreover, the chances of favorable outcome declined not only between the categories older and younger than 80 years, there was a linear relationship between outcome after 3 months and age from 20 to 90 years $(p<0.001$; Figs. 1 , $2)$. The average mRS after 3 months increased by 1 point mRS every 26 years advancing age.

The age dependent decline of outcome was not the result of decreasing recanalization success or higher rates of bleeding complications (there was only a trend for higher rates). This indicates that endovascular stroke therapy in the elderly is as effective as in young patients and that other factors such as less cerebral reserve capacity contribute to the worse outcome with advancing age. Similarly, a large IVT trial found a similar treatment effect of IVT in patients older and younger than 80 years (NNT 8.5 vs. 8.2), and in the IST-3 trial IVT showed even a greater benefit in patients older than 80 years than in younger patients [5, 29]. From these findings of the IVT treatment effect and our data on endovascular therapy, we conclude that advanced age should not be used to generally advise against IVT or endovascular treatment in acute stroke. The efficacy of endovascular treatment is preserved even above the age of 80 years and an upper age limit for its use does not seem to be justified.

Our study has several limitations. One of two major limitations is the type of analysis. The analysis was performed retrospectively on data that had been collected prospectively and continuously and included all consecutive patients treated at our stroke center. The other main limitation is the selection of patients. Almost all patients underwent multimodal MR or CT imaging before treatment decisions were made. Therefore, it is likely that we had selected patients with better chances for good outcomes for endovascular treatment, but this selection bias for treatment decisions applies both for younger and older patients. Due to the lack of an untreated control group, we can only state on the recanalization efficacy of endovascular treatment and cannot state whether these patients benefit from therapy. In addition, the trend for more bleeding complications in the elderly might be non-significant due to the overall low rates of ICH.

In conclusion, the chances for favorable outcome after endovascular therapy decreased continuously in a linear manner from age 20 to 90 years. However, this decline was not related to lower recanalization rates or higher bleeding risk in the elderly. The recanalization efficacy of endovascular stroke therapy seems to be preserved also in the elderly and advanced age should not generally advise against the use of endovascular treatment in acute stroke. Future prospective randomized trials should not use an upper age limit for study patients to evaluate safety and efficacy of endovascular stroke treatment.

\section{Conflicts of interest None.}

Ethical standard The study was performed according to the ethical guidelines of the Canton of Bern and with corresponding permission.

\section{References}

1. Kelly-Hayes M, Beiser A, Kase CS, Scaramucci A, D“Agostino RB, Wolf PA (2003) The influence of gender and age on disability following ischemic stroke: the Framingham study. J Stroke Cerebrovasc Dis 12(3):119-126

2. Dennis MS, Burn JP, Sandercock PA, Bamford JM, Wade DT, Warlow CP (1993) Long-term survival after first-ever stroke: the Oxfordshire Community Stroke Project. Stroke 24(6):796-800 
3. Heuschmann PU, Kolominsky-Rabas PL, Misselwitz B, Hermanek P, Leffmann C, Janzen RW et al (2004) Predictors of inhospital mortality and attributable risks of death after ischemic stroke: the German Stroke Registers Study Group. Arch Intern Med 164(16):1761-1768

4. Sylaja PN, Cote R, Buchan AM, Hill MD (2006) Thrombolysis in patients older than 80 years with acute ischaemic stroke: Canadian Alteplase for Stroke Effectiveness Study. J Neurol Neurosurg Psychiatry 77(7):826-829

5. Mishra NK, Ahmed N, Andersen G, Egido JA, Lindsberg PJ, Ringleb PA et al (2010) Thrombolysis in very elderly people: controlled comparison of SITS International Stroke Thrombolysis Registry and Virtual International Stroke Trials Archive. BMJ 341:c6046

6. Mishra NK, Diener HC, Lyden PD, Bluhmki E, Lees KR (2010) Influence of age on outcome from thrombolysis in acute stroke: a controlled comparison in patients from the Virtual International Stroke Trials Archive (VISTA). Stroke 41(12):2840-2848

7. The NINDS t-PA Study Group (1997) Generalized efficacy of t-PA for acute stroke. Subgroup analysis of the NINDS t-PA Stroke Trial. Stroke 28(11):2119-2125

8. Poppe AY, Buchan AM, Hill MD (2009) Intravenous thrombolysis for acute ischaemic stroke in young adult patients. Can $\mathbf{J}$ Neurol Sci (Le journal canadien des sciences neurologiques) 36(2):161-167

9. Putaala J, Metso TM, Metso AJ, Makela E, Haapaniemi E, Salonen O et al (2009) Thrombolysis in young adults with ischemic stroke. Stroke 40(6):2085-2091

10. Meseguer E, Labreuche J, Olivot JM, Abboud H, Lavallee PC, Simon O et al (2008) Determinants of outcome and safety of intravenous rt-PA therapy in the very old: a clinical registry study and systematic review. Age Ageing 37(1):107-111

11. Engelter ST, Bonati LH, Lyrer PA (2006) Intravenous thrombolysis in stroke patients of $\geq 80$ versus $<80$ years of age- a systematic review across cohort studies. Age Ageing 35(6):572-580

12. Ford GA, Ahmed N, Azevedo E, Grond M, Larrue V, Lindsberg $\mathrm{PJ}$ et al (2010) Intravenous alteplase for stroke in those older than 80 years old. Stroke 41(11):2568-2574 Epub 2010/10/12

13. Toni D, Ahmed N, Anzini A, Lorenzano S, Brozman M, Kaste M et al (2012) Intravenous thrombolysis in young stroke patients: results from the SITS-ISTR. Neurology 78(12):880-887

14. The IMS Study Investigators (2004) Combined intravenous and intra-arterial recanalization for acute ischemic stroke: the Interventional Management of Stroke Study. Stroke 35(4):904-911

15. The IMS II Trial Investigators (2007) The Interventional Management of Stroke (IMS) II Study. Stroke 38(7):2127-2135

16. Ciccone A, Valvassori L, Nichelatti M, Sgoifo A, Ponzio M, Sterzi R et al (2013) Endovascular treatment for acute ischemic stroke. N Engl J Med 368(10):904-913
17. Furlan A, Higashida R, Wechsler L, Gent M, Rowley H, Kase C et al (1999) Intra-arterial prourokinase for acute ischemic stroke. The PROACT II study: a randomized controlled trial. Prolyse in acute cerebral thromboembolism. JAMA 282(21):2003-2011

18. Broderick JP, Palesch YY, Demchuk AM, Yeatts SD, Khatri P, Hill MD et al (2013) Endovascular therapy after intravenous t-PA versus t-PA alone for stroke. N Engl J Med 368(10):893-903

19. Kidwell CS, Jahan R, Gornbein J, Alger JR, Nenov V, Ajani Z et al (2013) A trial of imaging selection and endovascular treatment for ischemic stroke. N Engl J Med 368(10):914-923

20. Mono ML, Romagna L, Jung S, Arnold M, Galimanis A, Fischer $U$ et al (2012) Intra-arterial thrombolysis for acute ischemic stroke in octogenarians. Cerebrovasc Dis 33(2):116-122

21. Qureshi AI, Suri MF, Georgiadis AL, Vazquez G, Janjua NA (2009) Intra-arterial recanalization techniques for patients 80 years or older with acute ischemic stroke: pooled analysis from 4 prospective studies. AJNR 30(6):1184-1189

22. Kim D, Ford GA, Kidwell CS, Starkman S, Vinuela F, Duckwiler GR et al (2007) Intra-arterial thrombolysis for acute stroke in patients 80 and older: a comparison of results in patients younger than 80 years. AJNR 28(1):159-163

23. Pundik S, McWilliams-Dunnigan L, Blackham KL, Kirchner HL, Sundararajan S, Sunshine JL et al (2008) Older age does not increase risk of hemorrhagic complications after intravenous and/ or intra-arterial thrombolysis for acute stroke. J Stroke Cerebrovasc Dis 17(5):266-272

24. Chandra RV, Leslie-Mazwi TM, Oh DC, Chaudhry ZA, Mehta BP, Rost NS et al (2012) Elderly patients are at higher risk for poor outcomes after intra-arterial therapy. Stroke 43(9):2356-2361

25. Galimanis A, Jung S, Mono ML, Fischer U, Findling O, Weck A et al (2012) Endovascular therapy of 623 patients with anterior circulation stroke. Stroke 43(4):1052-1057

26. Jung S, Schindler K, Findling O, Mono ML, Fischer U, Gralla J et al (2012) Adverse effect of early epileptic seizures in patients receiving endovascular therapy for acute stroke. Stroke 43(6):1584-1590

27. Jung S, Mono ML, Fischer U, Galimanis A, Findling O, De Marchis GM et al (2011) Three-month and long-term outcomes and their predictors in acute basilar artery occlusion treated with intra-arterial thrombolysis. Stroke 42(7):1946-1951

28. Kase CS, Furlan AJ, Wechsler LR, Higashida RT, Rowley HA, Hart RG et al (2001) Cerebral hemorrhage after intra-arterial thrombolysis for ischemic stroke: the PROACT II trial. Neurology 57(9):1603-1610

29. Sandercock P, Wardlaw JM, Lindley RI, Dennis M, Cohen G, Murray G et al (2012) The benefits and harms of intravenous thrombolysis with recombinant tissue plasminogen activator within $6 \mathrm{~h}$ of acute ischaemic stroke (the third international stroke trial [IST-3]): a randomised controlled trial. Lancet 379(9834):2352-2363 